\title{
PALATALIZAÇÃO PROGRESSIVA DAS OCLUSIVAS ALVEOLARES COM A FRICATIVA/S/ EM CONTEXTO ANTERIOR NA CIDADE DE MACEIÓ
}

\author{
ALMIR ALMEIDA OLIVEIRA*
}

RESUMO: Este trabalho investiga, sob a ótica da Sociolinguística Variacionista (LABOV, 2008 [1972]), os processos fonéticos/fonológicos da palatalização progressiva das oclusivas alveolares com a fricativa $/ \mathrm{S}$ / em contexto anterior, como em palavras do tipo gos [t]o e des[d\}]e, produzidos no Português Brasileiro falado em Maceió, contrapondo os dados linguísticos coletados com as variáveis externas (idade, sexo e escolaridade) e internas (contexto seguinte, acento, tamanho da palavra, vozeamento e fronteira lexical), a fim de identificar possíveis condicionantes de uso das variantes. A partir do método hipotético-indutivo empregado, os resultados obtidos apontam para a interação social entre a variável escolaridade e as variáveis idade e sexo, indicando que os informantes mais jovens e do sexo feminino são os maiores favorecedores desse processo de palatalização quando têm baixos índices de escolarização, ao passo que apresentam comportamento linguístico inverso, inibindo a palatalização, quando possuem maiores níveis de escolaridade. Assim, há indícios de que as formas palatalizadas padecem de uma valoração social negativa e é evitada por mulheres, jovens e pessoas escolarizadas, bem como sofrem condicionamento linguístico ao serem mais produtivas em certos ambientes fonéticos.

Palavras-chave: sociolinguística variacionista; palatalização progressiva; Maceió.

ABSTRACT: This work aims to investigate under the Variationist Sociolinguistic view (LABOV, 2008 [1972]) the phonetic/phonological processes of progressive palatalization of the alveolar stops with the fricative /S/ in the previous context, as in words at gos [t] $]$ o and des [d]] and, produced in Brazilian Portuguese spoken in Maceió, contrasting the linguistic data collected with external variables (age, sex and schooling) and internal variables (following context, accent, word size, voicing and lexical border) in order to identify possible use conditioning of the variants. Based on hypotheticalinductive method employed, the results obtained aim to the social interaction between the educational variable and the variables age and sex, indicating that younger and female informants are the most favorable in this process of palatalization whenever they have low rates of schooling, whereas they present opposite linguistic behavior, inhibiting the palatalization, when they have higher education levels. Thus, there are indications that the palatalized forms suffer from a negative social assessment and are avoided by women, young and schooling people, as well as suffer linguistic conditioning by being more productive in certain phonetic environments.

Keywords: sociolinguistic variationist; palatalization; Maceió.

* Professor Assistente da Universidade Estadual de Alagoas (UNEAL) e líder do Grupo de Estudo da variação linguística de Alagoas - GEVAL-AL.almirprofessor@yahoo.com.br 


\section{INTRODUÇÃO}

Este trabalho busca investigar o fenômeno da palatalização progressiva das oclusivas alveolares com a fricativa /S/ em posição de contexto anterior como uma característica do português moderno falado na capital alagoana; e como os fatores linguísticos e extralinguísticos se relacionam com os processos de palatalização, condicionando seus usos, inclusive, observando se a variação é estável ou se trata de uma mudança em curso.

Em Língua Portuguesa, a palatalização consiste em um processo autônomo e caracterizador, pois tem garantido uma série de particularidades linguísticas adquiridas historicamente - se comparadas com outras línguas, inclusive línguas neolatinas -, uma vez que há um conjunto de fonemas que não havia no latim, tendo, em sua maioria, surgido na época do galego e mantendo-se como marca característica do português.

Pelo processo de palatalização, o português integra consoantes palatais que não pertenciam à fonologia do latim clássico, mas que surgiram, ao que alguns estudos indicam, pela mesma motivação, ou seja, pela presença de um segmento vocálico ou fricativo de natureza palatal em suas proximidades (NEUSCHRANK; MATZENAUER, 2012), de modo que a palatalização mantém, como particularidade de realização, a presença de um gatilho fonético com minudências palatais.

Desse modo, a partir da percepção de Oliveira (2107) de que a palatalização progressiva das oclusivas alveolares se comporta como um processo fonológico diferente dependendo do segmento presente em contexto anterior às oclusivas, como nas formas 'muito' e 'gosto', este trabalho lança a hipótese que este tipo de palatalização recebe uma valoração social negativa principalmente estabelecida pelo ambiente educacional e afetando os falantes mais jovens e do sexo feminino.

O trabalho será organizado em três seções básicas. Na primeira, Coleta e tratamento dos dados, serão apresentados os detalhes metodológicos da coleta dos dados e seu tratamento estatístico. Na seção de Análises, os resultados obtidos através de programas computacionais serão apresentados em tabelas e gráficos, para o alcance de possíveis interpretações. Por fim, na Conclusão, serão feitas considerações sobre os resultados encontrados, bem como uma curta reflexão acerca do processo de variação das oclusivas alveolares em Maceió.

\section{COLETA E TRATAMENTO DOS DADOS}

A coleta dos dados para este trabalho foi realizada de acordo com as orientações metodológicas da Sociolinguística Variacionista, tendo como precursor Labov (2008 [1972]) e sendo rediscutida por Campoy e Almeida (2005), Sankoff e Labov (1979), Sankoff (1988) e, no Brasil, por Tarallo (1997), Mollica e Braga (2003) e outros.

Para a realização desta pesquisa, foram entrevistadas 48 pessoas estratificadas por sexo, masculino e feminino; idade, em três faixas que variam entre 18 e 35 anos, 36 e 55 anos e 56 e 80 anos; e escolaridade, em quatro níveis de educação, 
distribuídos em baixa escolaridade, ensino fundamental, ensino médio e ensino superior. Como critério para participar desta pesquisa, os colaboradores deveriam ser nascidos em Maceió, ou ter vindo para essa cidade com até cinco anos de idade e não ter morado mais de seis meses fora dela.

Todos os colaboradores foram voluntários e permitiram a gravação e a utilização dos dados, assinando o Termo de Consentimento Livre e Esclarecido ${ }^{1}$ - TCLE. Como a pesquisa é em Sociolinguística e são necessárias informações vernáculas sobre a língua, houve o cuidado em deixar o colaborador livre de tensões, para que pudesse falar espontaneamente suas opiniões ou narrativas de vida, conforme prega a metodologia sociolinguística: "um objetivo específico da metodologia variacionista é conseguir acesso ao que é referido como o 'vernáculo"”. (TAGLIAMONTE, 2006, p. 08)

Para a realização dessas entrevistas, utilizou-se um gravador digital de áudio Coby CXR 190, que permitiu gravar um total de 970 minutos de conversação com os 48 colaboradores, resultando uma média de 20':23" (vinte minutos e vinte e três segundos) por pessoa entrevistada. Foram coletados 3123 (três mil, cento e vinte e três) dados de fala espontânea em ambiente fonológico de realização das oclusivas alveolares $/ \mathrm{t} / \mathrm{e} / \mathrm{d} /$, antecedidas pela fricativa alveopalatal $/ \mathrm{S} / \mathrm{em}$ situações de fronteira e não fronteira lexical, obtendo realizações linguísticas como as visíveis na tabela 1 .

Todos os dados foram transcritos pelo próprio pesquisador em formato Textgrid no software Praat, que também permitiu a análise acústica dos dados e a confirmação de ocorrência ou não da palatalização das oclusivas alveolares em cada segmento analisado.

Tabela 1. Contextos palatalizáveis investigados em Maceió

\begin{tabular}{|c|c|c|}
\hline Sequência linguística & Transcrição fonética & Colaborador \\
\hline No dia treze de agosto & [nu die 'tre.zı di a.'gof.t'v] & $1 \mathrm{BCM}^{3}$ \\
\hline Desde pequeno & ['dez.dz। pe.'ke.nv] & $1 \mathrm{MBF}$ \\
\hline Uns tempo & [ũ] 'ţé.pv] & $1 \mathrm{BAF}$ \\
\hline Os dois é bom & [uz.dzol.'ze bõ] & $1 \mathrm{BBM}$ \\
\hline
\end{tabular}

Fonte: Autor (2017)

Após realizadas as etapas de coleta e transcrições dos dados, foram observados os possíveis padrões de realização da palatalização das oclusivas alveolares /t/ e /d/. O cuidado, assim, foi em garantir o cruzamento das variáveis sociais escolaridade, idade e sexo e as variáveis linguísticas com a forma palatalizada ou não das oclusivas alveolares em seus diferentes contextos de realização, a fim de notar se há ou não algum modo de condicionamento social às escolhas linguísticas

${ }^{1}$ O TCLE desta pesquisa foi aprovado pelo comitê de ética em pesquisa com o número de CAAE: 15231013.4 .0000 .5013

${ }^{2}$ No original: A specific goal of variationist methodology is to gain access to what is referred to as the "vernacular"'

${ }^{3} \mathrm{O}$ código apresenta informações sobre escolaridade, idade e sexo do colaborador. 
dos falantes acerca dessas variantes linguísticas palatalizadas. Afinal, de acordo com Cristófaro Silva et al (2012, p. 69):

\begin{abstract}
Podemos afirmar que o percurso que cada mudança linguística segue não é linear e depende de fatores diversos, inclusive os fatores sociais e pessoais. Uma vez que um determinado padrão esteja em mudança, várias forças de instabilidade podem interagir para que tal mudança siga caminhos não previsíveis. Assim, momentos de instabilidade e reorganização de padrões fonológicos de mudança podem ser observados.
\end{abstract}

A variação linguística está indubitavelmente atrelada às atividades sociais dos falantes, em toda sua esfera de valores, crenças, hábitos e atitudes, sendo, talvez, a língua, o elemento social mais sensível às exteriorizações de comportamento do indivíduo. As marcas sociais de valores chegam à língua em toda sua dimensão natural, desde os aspectos externos da discursividade, aos fragmentos linguísticos tipicamente estruturais da sintaxe, da morfologia e da fonética-fonologia.

Os estudos em sociolinguística variacionista buscam investigar as correlações estruturais que conectam os processos de variação linguística aos aspectos sociais valorativos definidores da identidade subjetiva do falante. De acordo com Mendoza-Denton (2003), toda pesquisa que se enquadra sob o rótulo de sociolinguística tem buscado compreender como os processos variacionais da língua estão indexados à prática social:

A pesquisa sociolinguística, sob várias correntes teóricas (teoria da acomodação, atos de identidade, redes sociais e comunidades de prática, entre outros) tem delineado o link entre a variação linguística indexada e a prática social. São estes estudos que proporcionam o elo mais forte e mais produtivo entre a sociolinguística variacionista com sua ênfase nas variáveis linguísticas e a antropologia linguística, com foco nas configurações de fala e suas consequências sociais. (MENDOZA-DENTON, 2003, p. 372)

A sociolinguística variacionista tem permitido a investigação das relações entre as práticas sociais - em toda a amplitude que o termo possa permitir - e as atitudes linguísticas dos falantes, observando, entre outras coisas, como a noção subjetiva de identidade - atrelada aos valores sociais distintivos - tem interferido na dinâmica linguística e direcionado os caminhos da variação e mudanças linguísticas, como pode ser verificado nos estudos na ilha de Martha's Vineyard (LABOV, 2008 [1972]), na cidade de Newfoundland, no Canadá (CLARKE, 1997), na ilha de British Isles, no Reino Unido (TRUDGILL, 1984), entre outros.

É de se esperar que, em qualquer pesquisa sociolinguística, os grupos de fatores sociais básicos como idade, sexo e escolaridade apresentem condicionamentos às escolhas linguísticas dos falantes, revelando que formas recebem marcas positivas e sobre as quais recaem os estigmas sociais.

A fim de estabelecer a relação entre as variáveis sociais e linguísticas e notar os condicionamentos externos dos fenômenos linguísticos, foi feita a codificação dos dados e sua consequente análise estatística. Para a realização da análise 
estatística dos dados desta pesquisa, foi utilizado o pacote de programa $\mathrm{R}^{4}$, em sua versão 3.3.1, desenvolvido para Microsoft Windows XP ou versão mais recente.

O R possui uma enorme quantidade de procedimentos estatísticos em milhares de pacotes livremente disponíveis na internet e que podem ser carregados opcionalmente. [...] Existem dezenas de interfaces para o R. Algumas exigem a memorização de numerosos comandos; outras oferecem uma interface com vários botões e itens de menu clicáveis (AQUINO, 2013, p. 03)

Nesta pesquisa foi utilizada a interface do RStudio ${ }^{5}$, que é um dos vários ambientes de desenvolvimento integrado (IDE) do $\mathrm{R}$ e funciona a partir da execução de scripts computacionais, apresentando funções para distribuição de probabilidade, testes estatísticos e geração de gráficos (GRIES, 2013).

Dois testes estatísticos foram realizados no $\mathrm{R}$ : o teste da razão da máxima verossimilhança (TRMV) e o teste de Wald (TW). O TW analisa a significância estatística entre fatores no interior das variáveis independentes, permitindo identificar fatores que apresentam efeitos estatisticamente diferentes da média dos efeitos dos fatores em uma variável independente.

O TRMV analisa a significância estatística entre variáveis independentes e permite identificar e hierarquizar as variáveis independentes estatisticamente significativas. A significância do teste TRMV mede a probabilidade de haver um erro ao negar a hipótese nula, de que a variável independente não condiciona a variável dependente. Tradicionalmente, nas ciências sociais, assume-se que há significância estatística quando a probabilidade de erro ao negar a hipótese nula é $<0,05$, de modo que quanto menor esse valor, maior a probabilidade do valor obtido no peso relativo estar correto.

\section{ANÁLISES}

Os dados com a fricativa alveopalatal /S/ em contexto anterior às consoantes oclusivas alveolares /t/ e /d/ devem ser investigados quanto às variáveis sociais idade, sexo e escolaridade e quanto às variáveis linguísticas contexto seguinte, acento, tamanho de palavra, vozeamento e fronteira lexical.

A distribuição da palatalização das oclusivas alveolares com a fricativa /S/ em contexto anterior é de 596 formas palatalizadas em 3123 ocorrências, o que corresponde a $19,1 \%$ de ocorrências palatalizadas. Um número bastante alto ao se comparar com outras pesquisas que tratam do processo de palatalização progressiva, como a desenvolvida por Mota e Rolemberg (1997) em Salvador, que obteve o percentual de palatalização de 2,4\%; e a realizada por Henrique e Hora (2012), em João Pessoa, que resultou em um percentual de palatalização de $10,5 \%$.

Seguindo a rotina de análise do $\mathrm{R}$, a variável linguística tamanho da palavra obteve o maior p-valor na correlação das variáveis, um valor acima de 0,05 , o

\footnotetext{
${ }^{4}$ Disponível em: http://cran.at.r-project.org/.

${ }^{5}$ Disponível em: http://www.rstudio.org/.
} 
que não permite o descarte da hipótese nula que afirma que todas as variáveis são iguais, logo, não há constatação estatística da significância deste grupo de fator para o processo de palatalização das oclusivas alveolares, levando ao seu descarte da análise.

A análise estatística dos dados revela que há uma significativa interação entre as variáveis externas idade e escolaridade, de modo que essa interação é assumida como fator de análise na pesquisa. $\mathrm{O}$ gráfico 1 ilustra como a interação entre as variáveis idade e escolaridade está interferindo no processo de palatalização das oclusivas alveolares produzidas por falantes de Maceió.

Gráfico 1. Palatalização das oclusivas alveolares e interação entre idade e escolaridade no modelo com a fricativa $/ \mathrm{S} /$ em contexto anterior às oclusivas (continua)

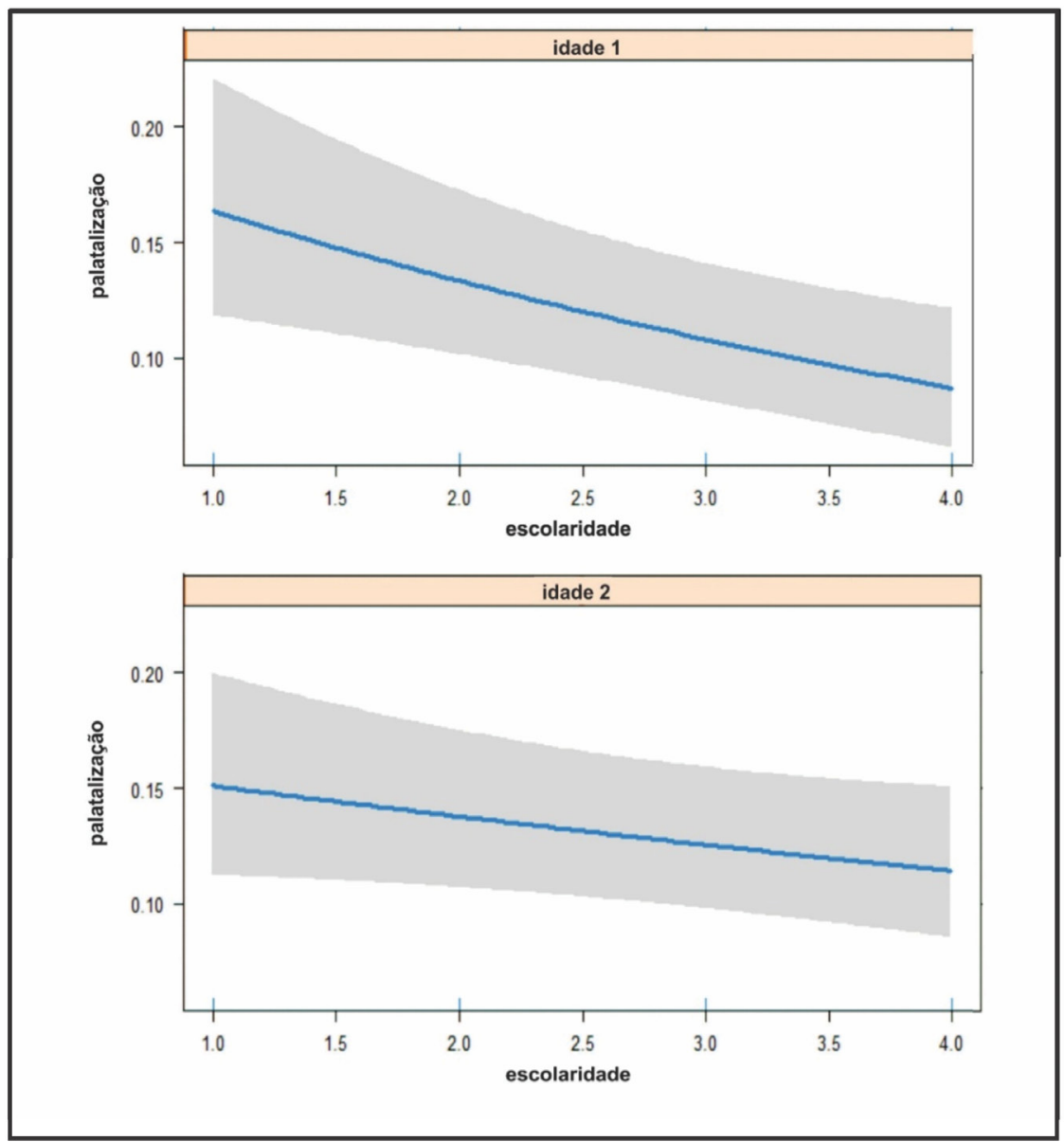


Gráfico 1. Palatalização das oclusivas alveolares e interação entre idade e escolaridade no modelo com a fricativa $/ \mathrm{S} /$ em contexto anterior às oclusivas (conclusão)

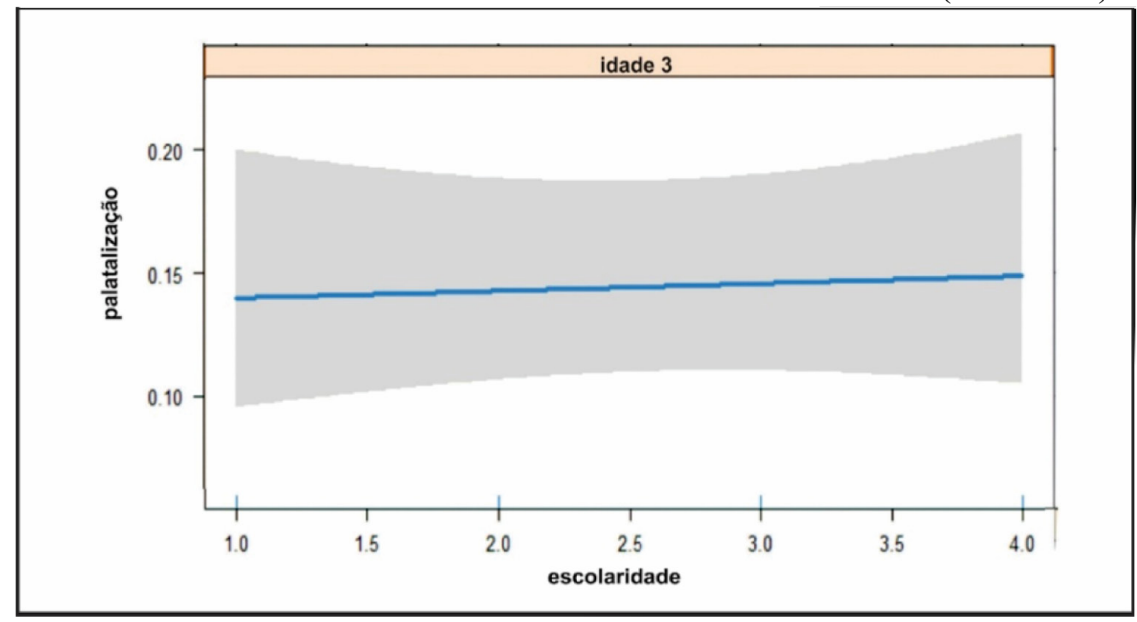

Fonte: Autor (2017).

O gráfico 1 ilustra como a interação entre a idade e escolaridade interfere nos efeitos da palatalização das oclusivas alveolares e revela que, dependendo da idade do falante, sua sensibilidade é alterada em relação à escolaridade, pois como se vê, os jovens, no primeiro nível etário, apresentam probabilidade de realização de uma forma palatalizada em cerca 0.17 se tiverem baixa escolaridade, sendo os maiores produtores de formas palatalizadas nesse nível de escolaridade; mas também apresentam os menores índices de condicionamento da variante palatalizada se têm ensino superior, contrapondo uma probabilidade de realização de 0.08 , contra 0.12 para colaboradores da segunda faixa etária (36 a 55 anos) e 0.15 para os colaboradores mais velhos.

A informação mais importante é a presença de uma leve inversão de comportamento linguístico correlacionada à interação entre escolaridade e idade, uma vez que enquanto os jovens, com idade entre 18 e 35 anos, também expressam uma maior resistência de uso da variante palatalizada, apresentando os maiores e os menores índices de realização palatalizada (contrapondo os colaboradores com baixa escolaridade e com ensino superior); conforme os colaboradores vão se tornando mais velhos, a curva descendente se atenua em relação à escolaridade, revelando que quanto maior a idade do falante, menor será o efeito da escolaridade sobre sua produção palatalizada.

De igual modo, a análise estatística revela que há uma significativa interação entre as variáveis sociais sexo e escolaridade. Para ilustrar como essa interação interfere nos efeitos de produção do processo de palatalização das oclusivas alveolares nos falantes da cidade de Maceió, vê-se o gráfico de dispersão com os seguintes resultados: 
Gráfico 2. Palatalização das oclusivas alveolares e a interação entre sexo e escolaridade no modelo com a fricativa $/ \mathrm{S} / \mathrm{em}$ contexto anterior às oclusivas

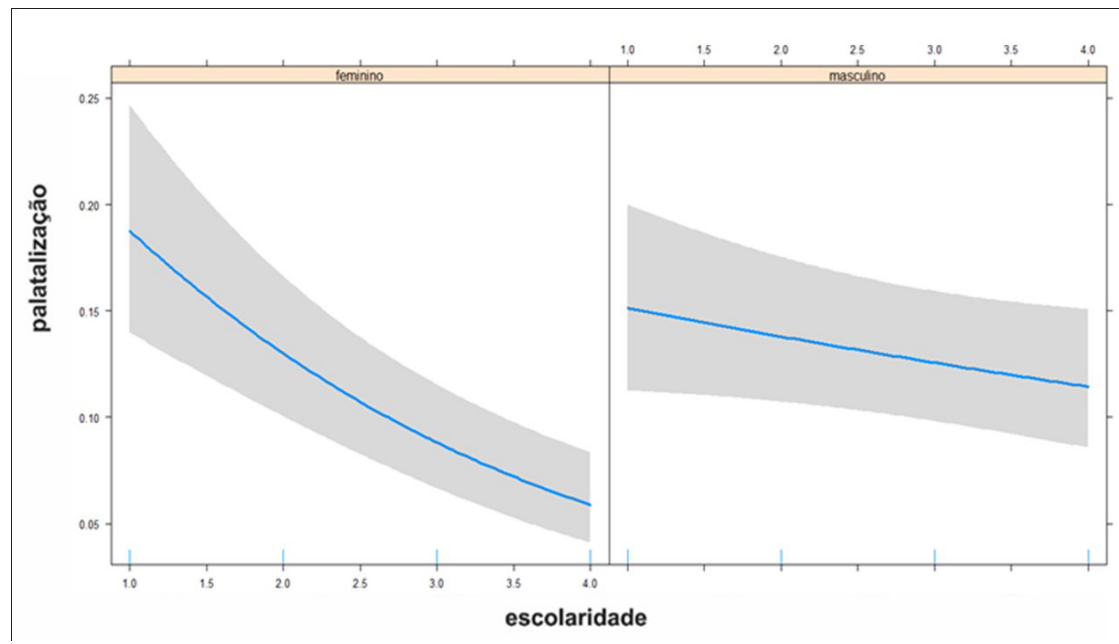

Fonte: Autor (2017)

É notório, neste caso, como a escolaridade interfere distintamente no comportamento linguístico do falante dependendo do seu sexo, pois embora as mulheres com baixa escolaridade apresentem os maiores índices de probabilidade de ocorrência de uma variante palatalizada, com um valor de 0.18 , em oposição ao valor probabilístico de 0.15 para os membros masculinos do mesmo nível de escolaridade, elas também aparecem com os menores valores de probabilidade de produção de uma variante palatalizada quando têm ensino superior, 0.7 ; enquanto os homens que também têm nível superior aparecem com um favorecimento à palatalização em 0.13 de valor probabilístico, revelando quase o dobro de possibilidades de ocorrência de uma variante palatalizada no ensino superior, se o falante for do sexo masculino.

Isso indica que embora a escolaridade esteja interferindo no processo de palatalização das oclusivas alveolares - no sentido de que quanto maior a escolarização do colaborador, a sua produção da variante palatalizada da oclusiva alveolar será menor -, essa interferência se dá de modo diferenciado se o falante for do sexo masculino ou feminino, uma vez que as mulheres apresentam uma maior rejeição da variante, conforme aumentam o nível de escolaridade. Sugerindo que escolarização está contribuindo com a valoração negativa das variantes palatalizadas na comunidade de fala investigada e afetando distintamente os membros do sexo masculino e do sexo feminino.

Passa-se, agora, a investigar como os contextos fonéticos interferem no processo de palatalização das oclusivas alveolares quando se tem a fricativa alveolar /S/ na posição de gatilho. Iniciando pelo contexto seguinte, o gráfico de dispersão ilustra como as vogais posteriores às oclusivas alveolares se realizam em função do processo de palatalização. 
Gráfico 3. Palatalização das oclusivas alveolares e a variável contexto seguinte em um modelo com a fricativa $/ \mathrm{S} / \mathrm{em}$ contexto anterior às oclusivas

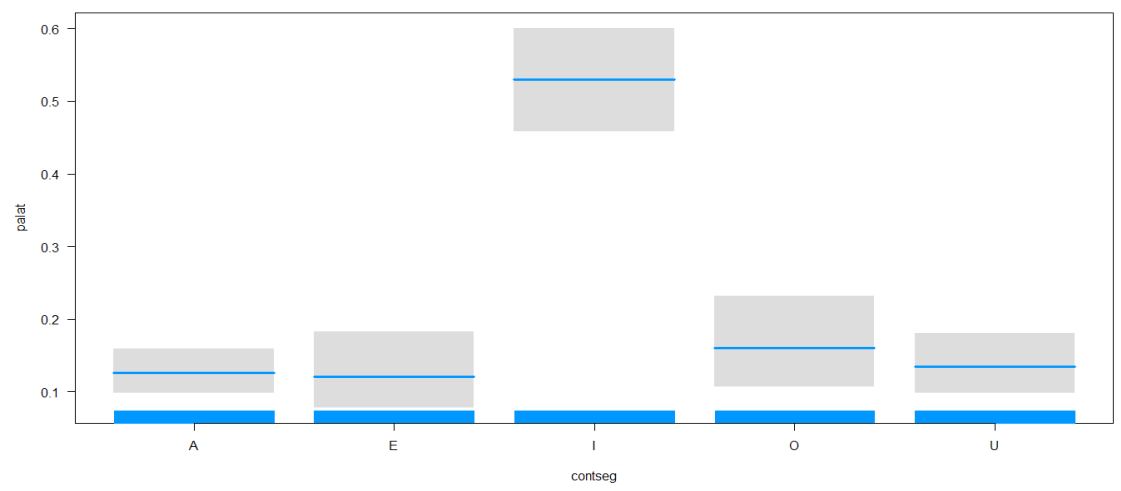

Fonte: Autor (2017)

Como se vê, a vogal /i/ apresenta um alto índice de significância probabilística completamente desproporcional em relação às demais vogais da variável, apontando uma probabilidade média maior que 0.5 de ocorrência da palatalização das oclusivas alveolares, enquanto todas as outras não chegam à 0.2 .

A fim de confirmar o que já se vê no gráfico 3, a tabela 2 é apresentada com os números totais de realização, os percentuais de produção e os pesos relativos, que atestam como as vogais do contexto seguinte às oclusivas estão relacionadas ao processo de palatalização das oclusivas alveolares:

Tabela 2. Palatalização das oclusivas alveolares e a variável contexto fonético seguinte em um modelo com a fricativa $/ \mathrm{S} /$ em contexto anterior às oclusivas

\begin{tabular}{c|c|l|c|l}
\hline \multicolumn{1}{c}{ Contexto seguinte } & \multicolumn{1}{c}{ Apl./Total } & \% & Peso relativo & p-valor \\
\hline $\mathbf{A}$ & $1093 / 162$ & 14,8 & 0.38 & 0.000 \\
\hline $\mathbf{E}$ & $381 / 23$ & 6,0 & 0.37 & 0.007 \\
\hline $\mathbf{I}$ & $803 / 264$ & 32.9 & 0.83 & 0.000 \\
\hline $\mathbf{O}$ & $213 / 27$ & 12,7 & 0.45 & 0.285 \\
\hline Total & $633 / 120$ & 19,0 & 0.41 & 0.002 \\
\hline
\end{tabular}

Fonte: Autor (2017)

De acordo com os valores demonstrados na tabela 2, fica evidente como a presença da vogal /i/ no contexto seguinte à oclusiva favorece o processo de palatalização das oclusivas alveolares.

É possível que a vogal /i/ seja tão produtiva no contexto seguinte à oclusiva devido à sua natureza fonética que lhe caracteriza com o traço +coronal (CLEMENTS; HUME, 1996). Inclusive, essa é a única vogal a possuir esse traço 
articulatório, que tem demonstrado ser tão importante no processo de palatalização das oclusivas alveolares.

$\mathrm{O}$ fato da vogal /i/ alcançar um peso relativo de 0.83 e p-valor zero em posição de contexto seguinte assevera sua natureza condicionadora de realização das consoantes palatalizadas [d3] e [t], enquanto as demais vogais visivelmente não favorecem o processo de palatalização, havendo neutralidade da vogal /o/ que obteve um p-valor de 0.285 , o que impede de assegurar que o peso relativo de 0.45 seja estatisticamente distinto do ponto neutro 0.5 , e o desfavorecimento das vogais /a/, /e/ e /u/ que apresentaram peso relativo inferior ao ponto neutro 0,5 e p-valor $<0,05$.

Para dar continuidade às análises dos dados e com intuito de investigar se o acento tônico interfere no processo de palatalização das oclusivas alveolares, é apresentado um gráfico de dispersão que dispõe as variantes palatalizadas, de acordo com a tonicidade da sílaba em que se encontra a consoante oclusiva.

Gráfico 4. Palatalização das oclusivas alveolares e a variável acento em um modelo com a fricativa /S/ em contexto anterior às oclusivas

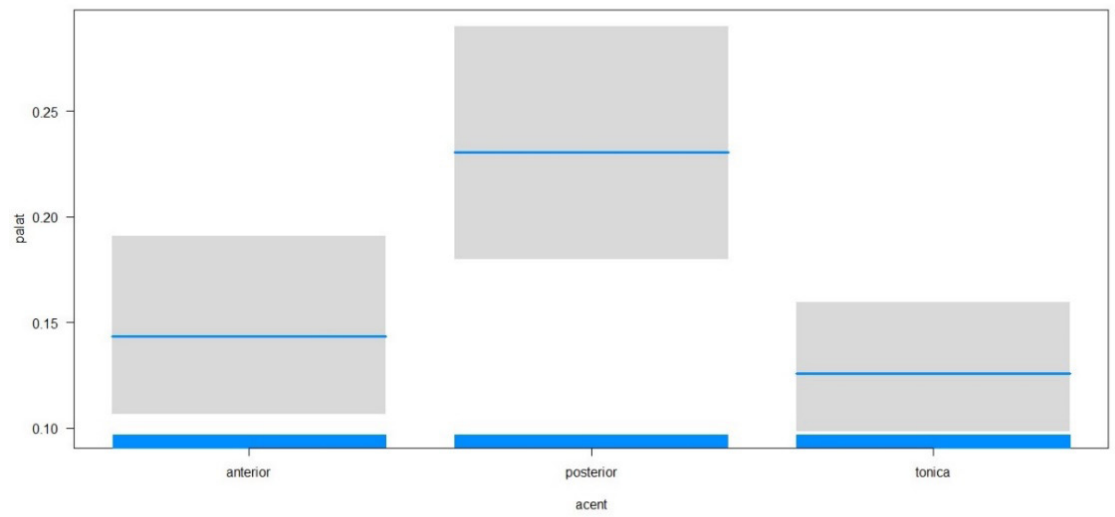

Fonte: Autor (2017)

A posição da sílaba em que se encontra a consoante oclusiva /t/ ou /d/ em relação ao acento tônico da palavra demonstra ser relevante a este processo de palatalização, principalmente se vier em contexto fonético posterior ao acento, como nas palavras "gosto" e "desde", apresentando um índice de probabilidade de realização palatalizada de 0.23 , favorecendo, portanto, a aplicação da regra de palatalização. Em contrapartida, o contexto de sílaba tônica apresenta valor probabilístico de realização da variante palatalizada de 0.08 , inibindo a regra de palatalização. Já o ambiente fonético anterior à sílaba tônica tem uma probabilidade de condicionamento das variantes palatalizadas em 0.14 , o que, pela disposição dos demais valores, significa não interferir no processo. 
Tabela 3. Palatalização das oclusivas alveolares e variável acento em um modelo com a fricativa /S/ em posição de gatilho

\begin{tabular}{|c|c|c|c|c|}
\hline Acento & Apl./Total & $\%$ & Peso relativo & p-valor \\
\hline pretônico & $664 / 115$ & 17,3 & 0.46 & 0.115 \\
\hline postônico & $563 / 209$ & 37,1 & 0.61 & 0.000 \\
\hline tônico & $1896 / 271$ & 14,3 & 0.43 & 0.000 \\
\hline Total & $3123 / 596$ & 19,1 & & \\
\hline
\end{tabular}

Fonte: Autor (2017)

Os valores da tabela 3 confirmam o favorecimento da sílaba postônica ao processo de palatalização das oclusivas alveolares que apresenta, além de um percentual mais elevado, peso relativo de 0.61 e p-valor zero. A sílaba tônica por outro lado, se apresenta como inibidora desse processo e aparece com um peso relativo de 0.43 e p-valor também zero. E a posição pretônica apesar de apresentar um peso relativo de 0.46 , o que desfavorece levemente o processo de palatalização, tem a entrada de um p-valor de 0.115 , o que indica que o peso relativo apresentado não é plenamente distinto do ponto neutro de 0.5 , revelando que a significância estatística do valor do peso relativo não é confiável. Logo, é possível assumir que há uma intercessão da posição do acento no processo de palatalização das oclusivas alveolares, no sentido que a sílaba tônica desfavorece a realização do fenômeno, a posição postônica favorece e a pretônica se encontra em uma posição próxima do ponto neutro.

Em seguida, é averiguado como o limite de fronteira lexical se comporta em relação ao processo de palatalização, uma vez que é investigada na pesquisa não apenas as palavras lexicais, mas também as palavras fonológicas que extrapolam os limites de fronteira lexical, em cujo contexto há realizações de variantes palatalizadas, em formas do tipo "um rapaz [t] $]$ entou assaltar" (1MBF) ou "esses [d3]ois" (1BAF).

Gráfico 5. Palatalização das oclusivas alveolares e a variável fronteira lexical em com a fricativa /S/ em contexto anterior às oclusivas

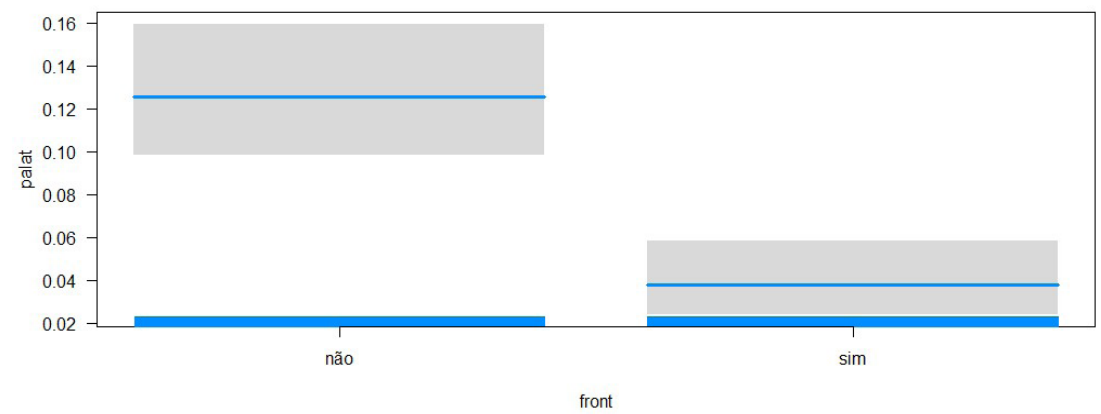

Fonte: Autor (2017) 
Embora seja possível a realização de formas palatalizadas fora dos limites da palavra lexical, esse contexto não é condicionador do processo, mas inibidor. Pois, na proporção em que se tem uma média de probabilidade de ocorrência de uma variante palatalizada em torno de 0.12 quando não se trata de contexto de fronteira, inversamente tem-se o valor probabilístico de apenas 0.04 de ocorrer a palatalização quando se tem um contexto de fronteira.

Fica ainda mais clara a relação da fronteira lexical com o processo de palatalização quando se vê a disposição percentual, os pesos relativos e p-valores, conforme dispostos na tabela 4:

Tabela 4. Palatalização das oclusivas alveolares e a variável fronteira lexical em um modelo com a fricativa /S/ em posição de gatilho

\begin{tabular}{c|c|c|c|c}
\hline Fronteira & Apl./Total & \% & Peso relativo & p-valor \\
\hline Sim & $1115 / 44$ & 3,9 & 0.34 & 0.000 \\
\hline Não & $2007 / 552$ & 27,5 & 0.66 & 0.000 \\
\hline Total & $3123 / 596$ & 19,1 & & \\
\hline
\end{tabular}

Fonte: Autor (2017)

Conforme se verifica na tabela 4, a realização de variantes palatalizadas é consideravelmente distinta quando se tem o contexto de fronteira, com taxa percentual menor que 5\% quando se trata de uma fronteira lexical e $27,5 \%$ quando o contexto é de não fronteira. Tal distorção de proporção reflete no peso relativo, cujos valores revelam que a posição de fronteira lexical inibe o processo de palatalização com 0.34 e a não fronteira favorece o processo, com valor de 0.66 , o que é confirmado com o p-valor zero que assegura a impossibilidade dos pesos relativos apresentados serem idênticos ao ponto neutro 0.5 .

Já quando se trata do vozeamento das oclusivas alveolares, o objetivo é descobrir se o fato da consoante ser vozeada ou desvozeada - /d/ ou /t/, respectivamente - interfere no processo de palatalização.

O gráfico 6 mostra como o vozeamento da consoante oclusiva/d/ se manifesta desfavorecendo o processo de palatalização, apresentando um valor de probabilidade de realização palatalizada de cerca de 0.01 - um valor extremamente baixo. Por outro lado, quando se tem a variante desvozeada $/ \mathrm{t} /$, a probabilidade de favorecimento do processo de palatalização é de cerca de 0.13 . 
Gráfico 6. Palatalização das oclusivas alveolares e a variável vozeamento em um modelo com a fricativa /S/ em posição de gatilho

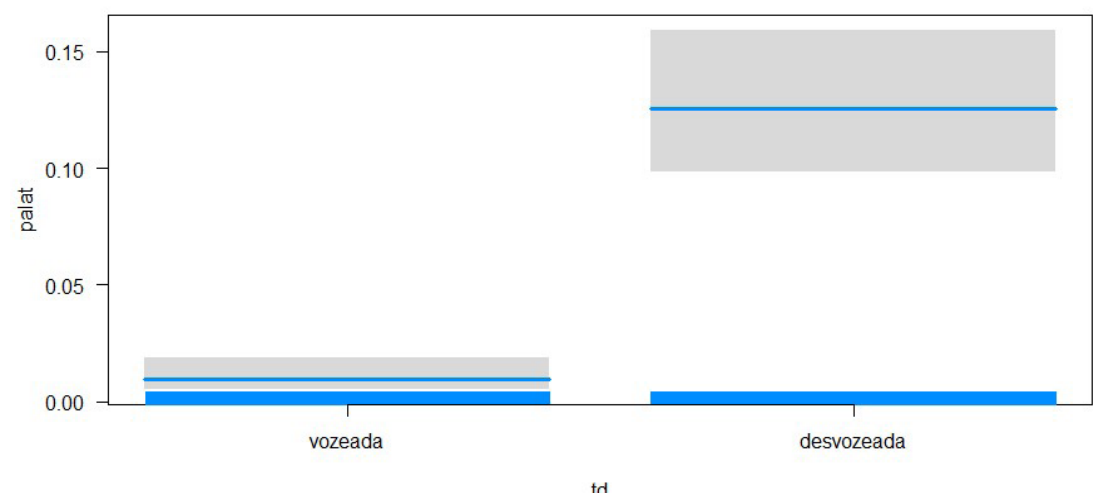

Fonte: Autor (2017)

A disposição dos dados quanto à correlação do vozeamento das consoantes oclusivas alveolares com o processo de palatalização pode ser visto com mais detalhes na tabela 5 :

Tabela 5. Palatalização das oclusivas alveolares e a variável vozeamento em um modelo com a fricativa / $\mathrm{S}$ / em contexto anterior às oclusivas

\begin{tabular}{|c|c|c|c|c|}
\hline Vozeamento & Apl./Total & $\%$ & Peso relativo & p-valor \\
\hline vozeada & $789 / 18$ & 2,3 & 0.22 & 0.000 \\
\hline desvozeada & $2334 / 578$ & 24,8 & 0.78 & 0.000 \\
\hline Total & $3122 / 595$ & 19,1 & & \\
\hline
\end{tabular}

Fonte: Autor (2017)

Com uma quantidade de apenas 19 realizações palatalizadas em um contexto de vozeamento, de um total de 801 ocorrências de palavras com a consoante /d/, fica bastante visível como a presença da consoante vozeada inibe o processo de palatalização das oclusivas alveolares, resultando em um percentual de 2,3\% e um peso relativo de 0.22 , confirmado por um p-valor zero. Por outro lado, quando se trata da consoante desvozeada /t/, há um amplo favorecimento do processo, com uma taxa percentual de $24,8 \%$, um peso relativo de 0.78 e p-valor zero, comprovando o condicionamento do processo ao desvozeamento da consoante oclusiva alveolar.

É possível que isso aconteça devido às características articulatórias empregadas no processo de palatalização das oclusivas alveolares, uma vez que sua energia articulatória é concentrada na região anterior da cavidade bucal, que é o mesmo ponto de realização das consoantes alveolares desvozeadas, ao passo que as consoantes vozeadas acrescem de mais um movimento articulatório, a vibração 
das pregas vocálicas localizadas na laringe, sendo esse um ponto distante da cavidade bucal anterior (BATTISTI; ROSA, 2012). Dessa forma, a aproximação do ponto de articulação da consoante desvozeada /t/ com os demais segmentos fonéticos empregados na palatalização a faz favorecer o processo.

\section{CONCLUSÃo}

O principal objetivo deste artigo foi apresentar uma análise variacionista do processo de palatalização das oclusivas alveolares em Maceió com a fricativa /S/ em posição de gatilho, com o intuito de investigar e descobrir as correlações linguísticas e sociais condicionantes de tal processo, a partir da qual se torna possível salientar que:

- A variável tamanho da palavra não exerce influência no processo;

- A posição postônica favorece o processo;

- No contexto seguinte às oclusivas, a presença da vogal anterior alta /i/ é a mais produtiva;

- Há interação entre escolaridade e idade, demonstrando que quanto mais jovem, maior a sensibilidade do falante aos efeitos normativos da escola;

- A interação entre sexo e escolaridade é significativa, revelando que os efeitos da escolaridade são mais perceptíveis com o público feminino.

O comportamento da variável tamanho de palavra contrariou a hipótese inicial de que quanto maior a palavra, também maior seria a possibilidade de palatalização e não demonstrou significância estatística, semelhante ao estudo desenvolvido por Souza Neto (2014) em Aracaju.

A posição postônica apresentou comportamento favorável à realização da variante palatalizada, divergindo dos resultados apresentados por Souza Neto (2014), e contrariando a hipótese inicial de que seria a posição tônica a maior favorecedora do processo de palatalização.

Quanto à correlação do contexto seguinte com o processo de palatalização, o contexto com a fricativa /S/ em posição de gatilho se mostrou favorecido com a presença da vogal anterior alta / $\mathrm{i}$ / localizada após a oclusiva, revelando consonância com outras pesquisas sobre a palatalização, como Bisol (1991), Santos (1996), Carvalho (2002), Pagotto (2004) e Souza Neto (2014).

Possivelmente, esse contexto é favorecedor do processo de palatalização por apresentar fones portadores do traço +coronal em posição anterior (gatilho) e posterior à oclusiva. Como há uma ordenação em conjunto dos traços dos fonemas, é de se esperar que a presença do traço +coronal em três fones consecutivos favoreça o espraiamento do traço +contínuo à consoante oclusiva, favorecendo sua realização africada.

A variável linguística vozeamento revela que a consoante desvozeada /t/, como esperado, favorece o processo de palatalização, ao passo que a consoante vozeada /d/ o restringe, resultado que corrobora com pesquisas anteriores sobre 
a palatalização progressiva, pois os trabalhos que investigaram esse grupo de fator, constataram que o desvozeamento da consoante favorece o processo de palatalização (MOTA; ROLEMBERG, 1997), (SOUZA NETO, 2014) e (HORA, 1990), o que sugere que independente do dialeto falado, o fator [-voz] exerce um papel favorável à aplicação da regra de palatalização.

De igual modo, a variável fronteira lexical revelou que, embora seja possível a palatalização das consoantes oclusivas em palavras fonológicas que extrapolem os limites das palavras lexicais, sua realização é bastante limitada e sua produtividade é estatisticamente não significativa. Sendo, consequentemente, o fator de não fronteira mais significativo no contexto de investigação. Resultado semelhante aos obtidos por Pagotto (2004) e Souza Neto (2014).

A interação entre as variáveis sociais sexo e escolaridade no contexto da fricativa /S/ em posição de gatilho revela que as mulheres apresentam uma maior sensibilidade aos efeitos de valoração da escolarização às variantes linguísticas, no sentido de que quanto maior for a escolaridade da colaboradora, maior será sua resistência à realização das formas palatalizadas das consoantes. Tal reação social aponta a presença de uma marca social negativa nas variantes linguísticas palatalizadas na cidade de Maceió, já que são evitadas pelos falantes com maior nível de escolarização e ainda mais quando são mulheres.

A interação entre idade e escolaridade tem apontado que os efeitos da escolaridade sobre as escolhas das variantes linguísticas pelos falantes são mais intensos com colaboradores mais jovens, com idade entre 18 e 35 anos, condicionando-os a evitarem as formas palatalizadas e produzirem as formas oclusivas. Isso revela que as formas palatalizadas sofrem de certo estigma social e que o ambiente escolar vem se tornando o grande fomentador desse valor social negativo, sendo, portanto, sua influência maior entre os falantes mais jovens que frequentam ambientes educacionais.

Os dados sociais apontam, de uma forma geral, para o enfraquecimento das variantes palatalizadas, uma vez que genericamente as pessoas mais jovens, mais escolarizadas e do sexo feminino tendem a evitar essas formas e preferirem os fones oclusivos, o que indica que a palatalização progressiva das oclusivas alveolares com a fricativa /S/ em contexto anterior na cidade de Maceió recebe uma valoração social negativa, confirmando a hipótese inicialmente levantada.

Sabendo que a discussão não está encerrada e que novos trabalhos se tornam necessários para retratar novos ângulos de observação para essa imagem, este artigo tem a pretensão de se tornar uma ferramenta para futuras pesquisas sobre o fenômeno da palatalização das oclusivas alveolares, em especial sobre a palatalização progressiva.

\section{AGRADECIMENTOS}

Ao meu amigo e orientador no Doutorado, Prof. Dr. Aldir Santos de Paula; aos professores Dr. João Henrique, Dra. Elyne Vitório e Dr. Alan Jardel, pelas valiosíssimas contribuições dadas à produção deste trabalho. 


\section{REFERÊNCIAS}

AQUINO, J. A. R para cientistas sociais. Ilhéus, BA: EDITUS, 2014.

BATTISTI, E.; ROSA, R. S. Variação e mudança linguística: análise em tempo real da palatalização das oclusivas alveolares em um falar do rio grande do Sul. Web-Revista Sociodialeto. Vol. 2, n. 2, novembro de 2012. Disponível em < $<$ www.sociodialeto.com.br $>$. Acesso em 13 jan. 2016.

BISOL, L. Palatalization and its variable restriction. In: International Journal of Sociology of Language, Mouton, n. 89, p. 107-124, 1991.

CAMPOY, J. M. H.; ALMEIDA, M. Metodología de la investigación sociolinguística. Granada: Editorial Comares, 2005.

CARVALHO, S. A palatalização das plosivas dentais na fala de pescadores no norte e noroeste do Rio de Janeiro. 2002. Dissertação (Mestrado em Letras) Faculdade de Letras da UFRJ. Rio de Janeiro, 2002.

CLARKE, S. Language in Newfoundland and Labrador: past, present and future. Journal of the Canadian Association of Applied Linguistics. V. 19, 11-34, 1997.

CLEMENTS, G. N. The geometry of phonology features (1985). In: GOLDSMITH, J. (Org.) Phonological Theory: the essential readings. Massachusetts: Blackwell, 1999. p. 177-224.

CRISTÓFARO SILVA, Thaïs et al. Revisitando a palatalização no português brasileiro. In: Revista de estudos linguísticos. V. 20, n. 2, Belo Horizonte. p. 59-89, jul./dez. 2012. Disponível em: <http:// www.periodicos.letras.ufmg.br/>. Acessado em 10 de novembro de 2016 às $13 \mathrm{~h} 30 \mathrm{~min}$.

HENRIQUE, P.; HORA, D. Um olhar sobre a palatalização das oclusivas dentais no vernáculo pessoense. In: XXIV Jornada Nacional do Grupo de Estudos Linguísticos do Nordeste, 2012, Natal-RN. Anais... Natal: EDUFRN, 2012. p. 150-161.

HORA, D. A palatalização das oclusivas dentais: variação e representação não-linear. Tese (Doutorado em Letras) - Instituto de Letras, PUC-RS, Porto Alegre, 1990.

LABOV, W. Padrões Sociolinguísticos. São Paulo: Parábola, 2008.

MENDOZA-DENTON, N. Language and identity. In: CHAMBERS, J. K.; TRUDGILL, P..; SCHILLING-ESTES, N. (Eds). The Handbook of Language Variation and Change. Blackwell Publishing. 363-381. Disponível em: <http://www.blackwellreference. com/subscriber/ $\underline{\text { book} ? \mathrm{id}=\mathrm{g} 97814051169239781405116923}>$. Acessado em 12 de maio de 2016 às $15 \mathrm{~h} 40 \mathrm{~min}$.

MOLLICA, M. C.; BRAGA, M. L. Introdução à Sociolinguística: o tratamento da variação. São Paulo: Contexto, 2003.

MOTA, Jacira; ROLEMBERG, Vera. Variantes africadas palatais em Salvador. In: HORA, Demerval da. (Org.) Diversidade Linguística no Brasil. João Pessoa: Ideia, 1997. p. 131 - 140.

NEUSCHRANK, Aline.; MATZENAUER, Carmen Lúcia Barreto. A palatalização na diacronia do PB: o surgimento dos segmentos palatais à luz de teoria fonológica. In: Linguística. Montevidéu, vol. 27. p. 18 - 46, jun. 2012. Disponível em: $<$ http://www.scielo.edu.uy/scielo.php?script=sci arttext\&pid=S2079-312X201200020 0003 $>$ Acesso em 14 jan. 2014 às 9h30min. 
OLIVEIRA, A. A. Processos de Palatalização das oclusivas alveolares em Maceió. 2017. Tese (Doutorado em Letras e Linguística). Programa de Pós-Graduação em Letras e Linguística da Universidade Federal de Alagoas - PPGLL-UFAL, Maceió, 2017.

PAGOTTO, E. G. Variação e (') identidade. Maceió: EDUFAL, 2004.

SANKOFF, D. Variable rules. In: AMMON, U.; DTTMAR, N.; MATTEIR, K. J. (Eds.) Sociolinguistics: an international handbook of the science os language and society. Ney York: Walter de Gruyter, 1988. p. 984-998. (Tradução caseira de Maria Marta Pereira Scherre. Brasília, 1992: revista em 1993, incorporando sugestões detalhadas de Ivone Isidoro Pinto (UFRJ), Maria Thereza Gomes Fiorett (UFRJ) e Maria Clara Álvares Correa Dias (UnB).

SANKOFF, D.; LABOV, W. On the uses of variable rules. Language in Society, v. 8, n. 2, 1979. p. 189-221.

SANTOS, L. F. Realização das oclusivas /t/ e /d/ na fala de Maceió. 1996. Dissertação (Mestrado em Letras e Linguística). Programa de Pós-Graduação em Letras e Linguística da Universidade Federal de Alagoas - PPGLL-UFAL, Maceió, 1996.

SOUZA NETO, A. F. Realizações dos fonemas /t/ e /d/ em Aracaju - Sergipe. Aracaju: Editora UFS, 2014

TAGLIAMONTE, S. A. Analyzing Sociolinguistic Variation. New York: Cambridge University Press, 2006.

TARALLO, F. A pesquisa socio-linguística. Série Princípios. São Paulo: Ática,1997.

TRUDGILL, P. Language in the British Isles. Cambridge: Cambridge University Press, 1984. 